\title{
Various Men's Body Shapes and Drops for Developing Menswear Sizing Systems in the United States
}

\author{
Su-Jeong Hwang Shin • Cynthia L. Istook* $*$ Jin Hee Lee** ${ }^{\dagger}$ \\ Dept. of Design-Apparel Design \& Manufacturing, Texas Tech University \\ *Dept. of Textile \& Apparel, Technology \& Management, North Carolina State University \\ **Dept. of Fashion Design \& Apparel Industry, Wonkwang University \\ Received October 20, 2011; Revised November 15, 2011; Accepted November 15, 2011
}

\begin{abstract}
Menswear body types are often labeled on garments (to indicate how the garments are designed to fit) with indicators of a size category such as regular, portly, and stout, athletic, or big and tall. A drop (relationships between the chest and waist girths) is related to the fit of a tailored suit. However, current standards are not designed for various drops or body types. There is not enough information of categorizing men's body shapes for the apparel sizing systems. In this article, a set of men's data from SizeUSA sizing survey was analyzed to investigate men's body shapes and drops. Factor analysis and a cluster analysis method were used to categorize men's body shapes. In the results, twenty-five variables were selected through the factor analysis and found four factors: girth factor, height factor, torso girth factor, and slope degree factor. According to the factor and cluster analysis, various body shapes were found: Slim Shape (SS - tall ectomorphy), Heavy Shape (HS - athletic, big \& tall, endomorphy and mesomorphy), Slant Inverted Triangle Shape (SITS - regular, slight ectomorphy and slight mesomorphy weight range from normal to slightly overweight), Short Round Top Shape (SRTS - portly and stout, endomorphy). Body shapes were related to fitting categories. SS and HS were related to big \& tall fitting category. SITS was related to regular. SRTS was related to portly and stout. Shape $1(31 \%)$ and Shape $2(26 \%)$ were related to current big \& tall category. Shape $3(34 \%)$ were related to regular. Shape $4(9 \%)$ were in portly and stout category. ASTM D 6240 standard was the only available standard that presented a regular fitting category. Various drops were found within a same chest size group; however, this study revealed great variances of drops by body shape.
\end{abstract}

Key words: Menswear, Sizing, Fit, Body shapes, Anthropometry

\section{Introduction}

The menswear industry is an important segment of the U.S. apparel business. Sales in the menswear market have been steadily growing over the past decade, especially in the luxury business (Business Wire, 2007; Kolesnikov-Jessop, 2010; Rueters, 2010). While the rate of growth slowed dramatically in late 2008 and 2009 , due to a global economic downturn, the market is still of major importance to the industry. Retailers, designers, and leading luxury brands (such as Roberto

Corresponding author

E-mail: jinhlee@wku.ac.kr

This study was supported by the Dillard's Services and $[\mathrm{TC}]^{2}$, providing SizeUSA men's data.
Cavalli, Georgio Armani, etc) are being more cautious about what they offer, aiming to provide value to the consumer and to pay closer attention to men's needs (Rueters, 2010) which are constantly evolving.

Men have become more concerned with their physical health, well-being, and image. Many have become more interested in fashion and have taken a more active role in managing their own wardrobes (KolesnikovJessop, 2010). These lifestyle changes, in addition to population changes, will have an impact on all segments of the menswear industry (tailored clothing, sportswear, active wear, comtemporary apparel and bridge apparel) (Stone, 2007).

Menswear size labeling systems are based on length or girth of body dimensions including neck, arm, chest, 
waist, and leg. A sizing system includes a range of sizes based on gradations of dimensions for a body type (Glock \& Kunz, 2005). Size indicators relate to dimensions of a garment component relative to a particular body dimension such as collar or inseam. The production of tailored men's clothing is a complicated process and is hindered by the dimensional sizing system currently in use (Stone, 2007).

A body type label is often attached to the garment or packaging and is included to provide the consumer with some confidence that the garment will fit, and complement, their body size and shape. For example, body type descriptors such as trim, slim, tapered, stocky, or husky are included to indicate garment circumference. The body type information can also be used as an indicator of a size category such as regular, portly and stout, athletic, or big and tall. This information provides the consumer with some, but often limited confidence, that a particular garment selected for purchase will fit their body type (Glock \& Kunz, 2005).

Different types of clothing require a unique subset of technical descriptors that provide information about whom that garments would fit. In the case of a tailored suit, for example, the "drop", which is the difference between the number given in the size of the suit and the pant size, is used to relate the fit. The drop values have been established according to the most often found relationship between the chest and waist girths for each fitting range, although drops are also influenced by body types, such as Regular, Athletic cut, and young man's silhouette Boswell (1993). Historically, most men's suits were made with a 6 inch drop which along with alterations could accommodate most body types. However, given the trends toward men having more athletic shaped bodies, as a result of increased interest in health and fitness, current manufacturers are changing their drop specifications to seven or eight inches (Dickerson, 2003).

Despite numerous studies over the years identifying garment fit problems due to outdated sizing standards, there has been no unified agreement as to how manufacturers can overcome these limitations (Connell et al., 2002; Kim, 2003; Shin \& Istook, 2007; Sieben \& Chen-Yu, 1992). As early as 1993, Boswell (1993) indicated potential fit problems in menswear special size categories such as $b i g \&$ tall. According to Chan et al. (2005), fit problems were related to inappropriate pattern grading related to sizing systems. The consumer's difficulty in finding garments with the correct fit also lowered the consumer's perception of quality (Sieben \& Chen-Yu, 1992). Garment fit problems are not gender specific, and in a previous study evaluating the shapes of female consumers by age and ethnicity, it was apparent that demographic factors were ignored when defining sizing systems and body shapes (Shin \& Istook, 2007).

There have been a number of attempts during the last decade to gather anthropometric data that would allow a better understanding of the adult population. CAESAR (Civilian American and European Surface Anthropometric Resource), SizeUK, SizeKorea, and SizeUSA have all been conducted to gain much needed information about the adult consumer. In the United Sates, the SizeUSA national sizing survey was led by $[\mathrm{TC}]^{2}$, a nonprofit organization. A representative sample of the entire male and female U.S. population was recorded by scanning over 10,000 people in 13 cities $\left([\mathrm{TC}]^{2}, 2004\right)$. To date however, there has been no indepth analysis comparing men's body shape and menswear sizing systems that might reveal factors that underlie fit problems.

Thus, the purpose of this study was to specifically evaluate the relationship of the drop to men's body shapes, and in general to determine if there are any easily identifiable changes in men's body shapes that should be taken into account in the current sizing standards. In this study, the objectives were 1) to investigate current drops and body types described within the ASTM standard, 2) to categorize men's body shapes for possible 'fine tuning' of menswear fitting categories and 3) to investigate the relationship of drops to men's body shapes that will affect in developing menswear sizing systems.

\section{Background}

\section{Menswear Sizing Systems and Fit Issues with Drops}

A sizing system is the term used to describe the 
total range of size and fitting combinations available in ready-to-made garments (Cooklin, 1992). A sizing system includes a range of sizes based on gradations of dimensions for a body type (Glock \& Kunz, 2005). A size chart is determined by two main factors: The type of garment and the body type of the target market (Aldrich, 1980).

Sizes of men's slacks, dress shirts, and tailored suits are based on dimensional measurements: length or girth of specific body parts including neck, arm, chest, waist, and leg. Dimensional sizing systems tend to have more consistency in measurements among styles and brands (Glock \& Kunz, 2005). In general, the intended purpose of a particular type of garment influences how strictly one must adhere to the sizing standards. For example, casual wear, such as a sweater can be offered in a much simpler sizing system, such as small, medium, etc, whereas a suit coat must be made assembled with attention to a greater specificity of fit. Measurements specified by size relate to dimensions of a garment component relative to a particular body part such as collar or inseam. For example, men's shirts are sized by two measurements: neck and sleeve length. The standard sizes most stores carry runs $14 \frac{1}{2} 2^{\prime \prime}$ to $171 / 2$ ", offered in $1 / 2$ inch increments with sleeve lengths running from 30-34 inches (Boswell, 1993). The production of men's tailored clothing is a complicated process. According to Stone (2008), men's tailored clothing is produced in the following proportioned sizes, with the number ranges representing chest girth measurements: Short 36-44, Regular 35-46, Long 37-48, Portly short 39-48, and Large 46, 48, 50 (Stone, 2008). A range in size from 36 to 50 is commonly offered for men's suits.

As noted above, men's casual wear is an area where there has been an attempt to simplify the sizing system because the traditional dimensional sizing system requires many combinations of chest and length measurements (Fringe, 2005). For example, sport shirts and sweaters are sized in a general sizing system such as small, medium, large, and extra large. Trousers are sized by waist and inseam measurements. In addition, all of the actual measurements in a sizing chart are determined by body types (Fringe, 2005). The commercial sizing systems offer a wide range of fittings.
For example, retailers of menswear in Europe provide six categories of fittings: Regular, slim, large, athletic, stocky, and portly (Cooklin, 1992). The categories of fitting are in each height group. According to Cooklin, the height groups are dependent upon two aspects: 1) the general height category such as short, medium or tall and 2) the range of heights covered within each height category, and their incremental values from size to size.

In the United States, a reference of menswear sizing systems is available through ASTM (American Society of Testing Material International Standard). ASTM D6240: Standard of body measurements for men sizes thirty-four to sixty is suggested to apparel manufacturers and retailers (ASTM, 2006). One limitation of this standard is that it is based on only a regular body type.

A drop has a big impact on the fit of a suit coat (Boswell, 1993). Current designer suits are typically sized based on a 7 inch drop (Dickerson, 2003; Stone, 2008; Tate, 2004), while non-designer suits have a 6 inch drop (Stone, 2008). According to Boswell, a 6 inch drop is the most common proportion among adult men and is referred to as a regular model. The 7 inch drop is considered to be the 'young man's silhouette' and now that its popularity is increasing, more manufacturers are offering it to retailers. The 8 inch drop, called the athletic cut, is the most difficult silhouette to find at retail, yet demand is increasing because of the interest in fitness. The athletic customer could require a drop of up to 10 inch, making it very difficult to find a suit at retail that will provide the desired fit.

Boswell (1993) indicated potential fit problems in special size categories. Big and tall men fall in the extra large range, sizes 48 to 52 , and those men who wear a size greater than 52 would have a problem finding clothing at retail. Portly and stout men have proportionately larger waists than the average man. The stout build tends to be a little taller than the portly body type. The portly man might have a smaller chest circumference than waist circumference. The portly and stout man would also have more difficulty finding clothing at retail. According to the NPD group (Stan, 2005), the main problems facing big and tall men in the U.S. were the lack of fashion and fit in 
offerings in the big and tall category of menswear.

\section{Previous Research of the Body Shapes}

Sheldon (1954) used photographs of young men to somatotype basic components of men's body types for medical purpose. Sheldon's main subdivisions of human morphological classification were 1) endomorphy (softness and obesity); 2) mesomorphy (muscularity and ruggedness); and 3) ectomorphy (linearity and poorly muscled). Each individual in the Sheldon system had varying degrees of each component rated on a 1-7 scale. Sheldon's classifications were primitive, yet at the time useful to describe men's body shapes.

In 1963, Douty expanded upon Sheldon's findings and combined the somatographic technique with silhouette photographs to develop body build and posture scales. However, Douty's posture scale was applied to only women's hourglass shapes. Stunkard and Albaum (1981) used nine line drawings of male and female bodies arranged from very thin to very heavy figures to assess perception of ideal body size. Farrell-Beck and Pouliot (1983) developed an experimental method to alter pant patterns using graphical somatometry techniques. They used five figure variations which were round hip, pearshaped hip, average hip, weight in front and weight in back. Heisey et al. (1986) used a graphical somatometry method to develop a mathematical framework for pattern alterations. Previous studies (Douty et al., 1974; Farrell-Beck \& Pouliot, 1983; Heisey et al., 1986; Sheldon, 1954; Stunkard \& Albaum, 1981) are useful references of the general body shapes based on a graphical somatometry method.

Lee (2004) used a set of men's 3D scan images and categorized head shapes based on a statistical approach with factor analysis and cluster analysis. In Lee's study (2004), four clusters represented characteristics of head types in girth, width length and depth. Lee's study (2004) is distinguished from other previous studies in that shapes were characterized by statistical analyses. There have been efforts to define the female body shape by analyzing data from 3D body scans. Connell et al. (2002) developed the Body Shape Analysis Scale (BSASC) to analyze body shape variations. Alexander et al. (2004) used BSASC to assess female body shape characteristics and fit problems. Simmons et al. (2004) developed shape identification software named Female Figure Identification TechniqueC (FFIT) for Apparel based on a mathematical analysis of data obtained from 3D body scans. Although these studies (Alexander et al., 2004; Connell et al., 2002; Simmons et al., 2004) were useful for analyzing female body shapes neither these nor previous studies (Douty et al., 1974; Farrell-Beck \& Pouliot, 1983; Heisey et al., 1986; Sheldon, 1954; Stunkard \& Albaum, 1981) were applied to men.

\section{Research Methods}

\section{Data Collection and Sample}

Male subjects were scanned during the SizeUSA national sizing survey (between 2002 and 2003), using $\mathrm{a}[\mathrm{TC}]^{2} 3 \mathrm{D}$ body scanner. Upon review of the entire data set it was noted that some subjects had missing measurements such as ankle heights, upper arms, and neck measurements. Therefore, only those subjects for which a complete data set was available (3686 subjects) was used in this study. The basic demographic information of subjects in this study is shown in $<$ Table $1>$. The majority of the subjects were Caucasian (47.3\%) with the second largest number being African American (19.2\%). With respect to age, the largest age group was $18-25$ (27\%) followed by the $36-45$ age group (22.7\%).

\section{Data Statistical Analysis Procedure}

First, it was necessary to determine if the subjects in each chest size group had drops that were similar to

Table 1. Demographic distribution of subjects

\begin{tabular}{l|c||c|c}
\hline \hline \multicolumn{1}{c|}{ Ethnics } & $\mathrm{n}(\%)$ & Age (year) & $\mathrm{n}(\%)$ \\
\hline White & $1744(47.3)$ & $18-25$ & $994(27.0)$ \\
\hline African-American & $709(19.2)$ & $26-35$ & $787(21.3)$ \\
\hline Hispanic & $637(17.3)$ & $36-45$ & $836(22.7)$ \\
\hline \multirow{2}{*}{ Others } & \multirow{2}{*}{$596(16.2)$} & $46-55$ & $625(17.0)$ \\
\cline { 3 - 4 } & & $56-65$ & $282(7.6)$ \\
\cline { 3 - 4 } & & $66+$ & $162(4.4)$ \\
\hline Total & $3686(100)$ & Total & $3686(100)$ \\
\hline
\end{tabular}


those defined by the ASTM menswear sizing system with the following null hypotheses:

Ho: SizeUSA men's drops would be different than the ASTM drops within the sizing system.

Ha: SizeUSA men's drops would be the same as the ASTM drops within the sizing system.

SizeUSA men's drop values (the differences between chest and waist) were compared to ASTM D 6240Standard Tables of Body Measurements for Men Sizes Thirty-Four to Sixty Regular (ASTM, 2006). The subjects' chest sizes were matched to the ASTM chest sizes with the following formula:

ASTM Chest- 0.5 inch $\leq$ Subject's chest girth measurements $\leq$ ASTM Chest +0.5 inch

The subjects were grouped according to chest sizes. In the result, 22 of the subjects (1\%) could not be matched with ASTM chest sizes because their chest sizes were out of the size ranges in the ASTM D 6240 standard. The null hypotheses were tested using a paired $t$-test to compare sample means with a $95 \%$ level of significance $(p<.05)$.

Second, men's body shapes were categorized to identify if various body shapes and drops exist in the population. In this study, Lee's (2004) shape analysis method was used to categorize men's body shapes. Like Lee's shape analysis method, factor analysis was used by collecting twenty five variables: weight, chest, hips, waist, upper arm, elbow, across shoulder, calf, thigh, center trunk, knee, armscye, neck, cross chest width, shoulder length, cross back width, ankle, crotch height, waist height, height, arm length (shoulder to wrist), crotch length total, waist length front, waist length back, and shoulder slope. The height and weight were recorded manually during the survey period because the body scanner was not able to obtain the height and weight.

The variables were selected through a variable screening process, and the factor scores were saved for cluster analysis to categorize men's body shapes. In addition, the following computed values were used to analyze men's upper body shapes and drops: 1) the difference between Hip and Chest girth; 2) the difference between Hip and Waist girth; 3) the difference between Chest and Waist girth (drop value); and 4) body mass index (BMI). Body mass index (BMI) was used as a measure of body fat based on height and weight as it applies to adult men. BMI was calculated by the formula: [(weight in pounds/height in inches ${ }^{2}$ ) *703].

The equation and interpretation of the BMI categories were based on the National Institute of Health's body mass index (National Institute of Health, 2006): Underweight (BMI of 18.5 or less), Normal weight (BMI 18.5-24.9), Overweight (BMI 25-29.9), and Obese (BMI of 30 or greater). In this study, the categorized body shapes were compared to Sheldon's classifications and current menswear fitting categories. The body shapes were compared by age groups and ethnicity groups.

\section{Results}

\section{Men's Body Dimensions and Drops in USA}

$<$ Table 2> shows the distributive information of the men's body dimensions and drops with each value of mean and standard deviation in this study. As shown in $<$ Table 2>, height $68.97 \mathrm{inch}$, weight $184.98 \mathrm{lbs}$, chest girth 42.64 inch, waist 36.86 inch, and hips 41.55 inch were the average body dimensions. The mean BMI value was 27.33, which is in the Overweight category.

Drops are commonly used in the apparel industry to develop menswear and manufacturers have been changing their specifications to 7 inch or 8 inch drops (Dickerson, 2003; Stone, 2008). However, as shown in $<$ Table $2>$, the average drop value, was 5.78 inch (Standard Deviation: 2.41, range from -5.50 to 14.09), and a drop of 7.41 inch and 8.73 inch would be values found at the $75^{\text {th }}$ and $90^{\text {th }}$ percentile, respectively. Thus, increasing the drop to 7 or 8 inches may not be prudent. The difference between hip and waist girth was 4.69 inch (Standard Deviation: 2.14, range from -2.43 to 12.01). Difference between hip and chest girth was -1.09 inch (Standard Deviation: 2.26, range from -12.06 to 9.20 ).

According to the mean and BMI, most of the men's bodies fell into two categories, either endomorphy (softness and obesity) or mesomorphy (muscularity and ruggedness). However, the standard deviations were sufficiently large which indicated that multiple body shapes might exist. 
Table 2. SizeUSA men's body dimensions and drops

(Unit: inches)

\begin{tabular}{|c|c|c|c|c|}
\hline Body dimensions & Mean & S.D. & 90 percentile & 75 percentile \\
\hline Height & 68.97 & 3.38 & 73.00 & 71.00 \\
\hline Weight (lbs.) & 184.98 & 38.29 & 233.50 & 205.01 \\
\hline Chest & 42.64 & 4.28 & 48.09 & 45.26 \\
\hline Waist & 36.86 & 5.15 & 43.35 & 39.55 \\
\hline Hips & 41.55 & 4.08 & 46.58 & 43.46 \\
\hline Across Shoulder & 16.98 & 1.35 & 18.73 & 17.83 \\
\hline Center Trunk & 64.78 & 3.97 & 69.81 & 67.25 \\
\hline Armscye & 18.67 & 1.67 & 20.72 & 19.72 \\
\hline Neck & 16.30 & 1.34 & 18.00 & 17.10 \\
\hline Waist Length Front & 18.38 & 2.39 & 21.30 & 20.04 \\
\hline Waist Length Back & 20.38 & 1.51 & 22.23 & 21.37 \\
\hline Shoulder Slope (Degrees) & 23.35 & 3.69 & 27.97 & 25.91 \\
\hline BMI & 27.33 & 5.27 & 34.00 & 30.00 \\
\hline Difference: Chest-Waist girth (Drop) & 5.78 & 2.41 & 8.73 & 7.41 \\
\hline Difference: Hip-Waist girth & 4.69 & 2.14 & 7.48 & 6.20 \\
\hline Difference: Hip-Chest girth & -1.09 & 2.26 & 1.73 & 0.39 \\
\hline
\end{tabular}

\section{Comparison of the Men's Drops to the ASTM Menswear Sizing System}

Men's drops were analyzed using a paired t-test to evaluate sample means to investigate whether the mean drop found in our study was different than the ASTM drop. When we compared our drop to ASTM D 6240, the mean drop was not significantly different at the $95 \%$ confidence level $(\mathrm{t}=-0.13015, p=0.8969)$. This result indicates that average SizeUSA men's drops might not be different from the ASTM's average drops in sizes ranging from 34 to 60 . However, when we analyzed men's drops in each chest size group, variances did exist within the same chest size group.

$<$ Table $3>$ shows the results from the comparison of the men's drops to ASTM D 6240. ASTM D6240 had a consistent 6 inch drop for the general sizes $(\mathrm{S}$, $\mathrm{M}$, and $\mathrm{L}$ ), and small drops (5.5 inch- -2 inch) for extra large sizes (XL-4XL). As shown in $<$ Table 3>, SizeUSA men's drops are close to ASTM drops in the size range $\mathrm{M}$ and $\mathrm{L}$. However, compared to ASTM drops (6 inch), subjects in the group of chest size 34 (size S) had even much smaller drops (4.75 inch).

$<$ Fig. 1> shows a graphical plot of the comparison of men's drops to ASTM D 6240. As shown in $<$ Fig. 1 $>$, both ASTM D6240 and SizeUSA have a downward curve indicating that the larger size groups have smaller drops compared to smaller size groups.

As shown in $<$ Fig. $1>$ and $<$ Table $3>$, SizeUSA men's average drops are similar to ASTM drops. However, we found that men's drops were varied within each size group. For example, as shown in $<$ Fig. $1>$ and $<$ Table 3>, subjects in the group of chest size 54 (3XL) had a larger standard deviation (3.83) showing drop ranges from -2.15 inch to $11.65 \mathrm{inch}$. This result indicated that various body shapes exist in any same size ranges, and current sizing system designed for a regular will not be applicable for the various body shapes.

Therefore, this is evident that sizing systems should be developed for more than one body shape. For developing a standard, defining each group will be necessary. However, drops are only way to describe men's body types in the United States, and there is no clear definition to provide these various men's body shapes in order for manufactures to develop menswear sizing systems.

\section{Factors Analysis for Grouping Variables}

According to the results above, it was necessary to categorize men's body shapes to identify various body 


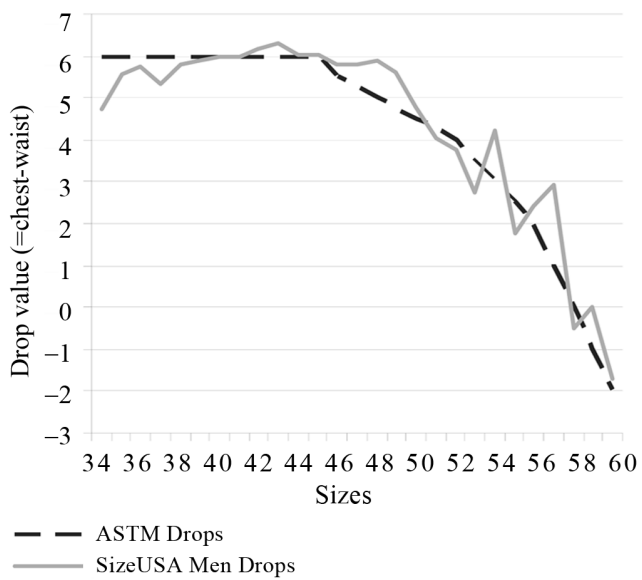

Fig. 1. Drop value ranges of the ASTM 6240 and SizeUSA men.

shapes. Lee's (2004) shape analysis method was used in this study, and as we indicated previously, twenty five variables were collected through the factor analysis. The data is summarized in $<$ Table $4>$ and four factors were found:

- Factor 1 (girth factor) was explained with weight, chest, hips, waist, upper arm, elbow, across shoulder, calf, thigh, center trunk, knee, armscye, mid neck, cross chest width, shoulder length, cross back width, and ankle.

- Factor 2 (height length factor) was explained with height, crotch height, waist height, and arm length.

- Factor 3 (torso length factor) was explained with crotch length total, waist length front and waist length back.

- Factor 4 (degree factor) was explained with shoulder slope degree. The cumulative percentage of the four factors was $79.765 \%$, suggesting considerably strong factors.

\section{Comparison of the Men's Body Shapes by the Cluster Analysis}

The factor scores above were used for the cluster analysis. $<$ Table $5>$ shows the frequency of the men's body shapes categorized after cluster analysis. In the results, four body shapes were defined: Slim Shape
Table 3. Comparison of the computed drops between ASTM D6240 and SizeUSA men

(Unit: inches)

\begin{tabular}{|c|c|c|c|c|c|c|}
\hline \multirow{2}{*}{\multicolumn{2}{|c|}{ Size }} & \multirow{3}{*}{$\begin{array}{r}\begin{array}{c}\text { ASTM } \\
\text { Drops }\end{array} \\
6.00\end{array}$} & \multicolumn{4}{|c|}{$\begin{array}{l}\text { SizeUSA Men Drops } \\
\text { (=chest-waist) }\end{array}$} \\
\hline & & & Mean & S.D. & Min. & Max. \\
\hline 34 & \multirow{4}{*}{$\mathrm{S}$} & & 4.75 & 1.30 & 1.82 & 6.69 \\
\hline 35 & & 6.00 & 5.56 & 1.76 & 0.44 & 9.4 \\
\hline 36 & & 6.00 & 5.75 & 1.91 & 0.28 & 9.38 \\
\hline 37 & & 6.00 & 5.33 & 1.82 & -1.39 & 10.08 \\
\hline 38 & \multirow{4}{*}{ M } & 6.00 & 5.81 & 1.92 & -0.74 & 10.22 \\
\hline 39 & & 6.00 & 5.90 & 2.00 & 1.03 & 11.14 \\
\hline 40 & & 6.00 & 5.97 & 2.07 & -0.11 & 11.15 \\
\hline 41 & & 6.00 & 5.96 & 2.21 & -0.63 & 11.96 \\
\hline 42 & \multirow{4}{*}{$\mathrm{L}$} & 6.00 & 6.18 & 2.22 & -1.06 & 13.25 \\
\hline 43 & & 6.00 & 6.29 & 2.24 & -0.45 & 13.26 \\
\hline 44 & & 6.00 & 6.02 & 2.33 & 0.52 & 12.89 \\
\hline 45 & & 6.00 & 6.02 & 2.44 & -0.89 & 12.21 \\
\hline 46 & \multirow{4}{*}{$\mathrm{XL}$} & 5.50 & 5.81 & 2.53 & -1.89 & 12.56 \\
\hline 47 & & 5.25 & 5.78 & 2.92 & -3.27 & 14.09 \\
\hline 48 & & 5.00 & 5.88 & 2.73 & -0.85 & 12.55 \\
\hline 49 & & 4.75 & 5.59 & 2.93 & -1.93 & 12.65 \\
\hline 50 & \multirow{4}{*}{$2 \mathrm{XL}$} & 4.50 & 4.78 & 2.77 & -2.26 & 10.49 \\
\hline 51 & & 4.25 & 4.06 & 3.67 & -2.91 & 12.38 \\
\hline 52 & & 4.00 & 3.75 & 3.14 & -2.88 & 8.80 \\
\hline 53 & & 3.50 & 2.72 & 2.85 & -1.97 & 9.03 \\
\hline 54 & \multirow{4}{*}{$3 \mathrm{XL}$} & 3.00 & 4.21 & 3.83 & -2.15 & 11.65 \\
\hline 55 & & 2.50 & 1.76 & 3.32 & -5.50 & 8.74 \\
\hline 56 & & 2.00 & 2.41 & 2.74 & -0.27 & 8.14 \\
\hline 57 & & 1.00 & 2.91 & 0.39 & 2.47 & 3.19 \\
\hline 58 & \multirow{3}{*}{$4 \mathrm{XL}$} & 0.00 & -0.50 & 2.64 & -2.92 & 2.69 \\
\hline 59 & & -1.00 & N/A & N/A & N/A & N/A \\
\hline 60 & & -2.00 & -1.70 & 2.32 & -3.37 & 0.95 \\
\hline
\end{tabular}

$\mathrm{t}=-0.130159, p=0.896963$

(31\%), Heavy Shape (26\%), Slant Inverted Triangle Shape (34\%), and Short Round Top Shape (9\%).

$<$ Table 6> show average factor scores and computed values in each body shape. $<$ Table $7>$ shows the distributive information of the body dimensions with each value of mean in each body shape group. $<$ Fig. $2>$ shows examples of the men's body shape that was defined and grouped by the factor and cluster analysis in this study.

As shown in $<$ Table $6>-<$ Table $7>$, Slim Shape 
Table 4. Factor analysis for grouping variables

\begin{tabular}{|c|c|c|c|c|c|}
\hline Body Dimensions & $\begin{array}{c}\text { Factor } 1 \\
\text { (Girth factor) }\end{array}$ & $\begin{array}{c}\text { Factor } 2 \\
\text { (Height factor) }\end{array}$ & $\begin{array}{c}\text { Factor } 3 \\
\text { (Torso length factor) }\end{array}$ & $\begin{array}{c}\text { Factor } 4 \\
\text { (Degree factor) }\end{array}$ & Communality \\
\hline Weight & 0.948583 & 0.198659 & 0.062016 & -0.05096 & 0.945719 \\
\hline Chest & 0.946441 & -0.0278 & 0.11289 & -0.01359 & 0.909452 \\
\hline Hips & 0.937303 & 0.082029 & -0.07654 & -0.06192 & 0.894958 \\
\hline Waist & 0.923036 & -0.03252 & 0.043392 & -0.1335 & 0.872758 \\
\hline Upper Arm & 0.912105 & 0.058683 & 0.028413 & 0.025465 & 0.836835 \\
\hline Elbow & 0.895053 & 0.082047 & 0.035702 & -0.00501 & 0.809151 \\
\hline Across Shoulder & 0.876472 & 0.028828 & 0.169312 & 0.261488 & 0.866076 \\
\hline Calf & 0.846556 & 0.100814 & 0.034187 & -0.01464 & 0.728204 \\
\hline Thigh (Max) & 0.842694 & 0.178294 & -0.09194 & 0.038095 & 0.751825 \\
\hline Center Trunk & 0.841271 & 0.275175 & 0.201666 & -0.14018 & 0.843778 \\
\hline Knee & 0.83491 & 0.253113 & 0.007191 & -0.09374 & 0.769981 \\
\hline Armscye & 0.831847 & 0.154789 & 0.142169 & -0.02326 & 0.736682 \\
\hline Neck (Mid neck) & 0.825204 & -0.08016 & 0.107142 & 0.013086 & 0.699037 \\
\hline Cross Chest Width & 0.748693 & -0.0305 & 0.102927 & -0.29658 & 0.660022 \\
\hline Shoulder Length & 0.709563 & 0.101247 & 0.190063 & 0.318974 & 0.651599 \\
\hline Cross Back Width & 0.689826 & 0.075048 & 0.183884 & 0.380172 & 0.659836 \\
\hline Ankle & 0.660267 & 0.290784 & 0.02324 & -0.11551 & 0.53439 \\
\hline Crotch Height & -0.08452 & 0.934799 & 0.003875 & 0.076774 & 0.886903 \\
\hline Waist Height & 0.141089 & 0.879669 & -0.40989 & -0.00556 & 0.961765 \\
\hline Height & 0.207677 & 0.869258 & 0.18111 & 0.02785 & 0.832316 \\
\hline Arm_Length (Shoulder_to_Wrist) & 0.173593 & 0.862537 & 0.088652 & -0.02931 & 0.782823 \\
\hline Waist Length (Front) & 0.378659 & -0.10517 & 0.845643 & -0.09935 & 0.879427 \\
\hline Waist Length (Back) & 0.191792 & 0.239131 & 0.841591 & 0.044051 & 0.804183 \\
\hline Crotch Length Total & 0.576324 & 0.276448 & -0.68577 & -0.10837 & 0.890598 \\
\hline Shoulder Slope (Degrees) & -0.08548 & 0.026409 & -0.0211 & 0.851165 & 0.732932 \\
\hline Eigenvalue & 13.2294 & 3.35751 & 2.15262 & 1.2017 & \\
\hline Variance $(\%)$ & 52.918 & 13.43 & 8.61 & 4.807 & \\
\hline Cumulative $(\%)$ & 52.918 & 66.348 & 74.958 & 79.765 & \\
\hline
\end{tabular}

Table 5. Results of the men's body shape groups and the demographic distribution

\begin{tabular}{|c|c|c|c|}
\hline Body Shapes & $\begin{array}{c}\text { Sheldon's } \\
\text { Classifications }\end{array}$ & $\begin{array}{l}\text { Menswear Fitting } \\
\text { Categories }\end{array}$ & $\mathrm{n}(\%)$ \\
\hline $\begin{array}{c}\text { Shape 1: } \\
\text { Slim Shape (SS) }\end{array}$ & Ectomorphy & Tall, Athletic & $1153(31.0)$ \\
\hline $\begin{array}{c}\text { Shape 2: } \\
\text { Heavy Shape (HS) }\end{array}$ & Endomorphy and mesomorphy & Big \& Tall, Athletic & $969(26.0)$ \\
\hline $\begin{array}{l}\text { Shape 3: } \\
\text { Slant Inverted Triangle Shape (SITS) }\end{array}$ & $\begin{array}{l}\text { Somewhat or not mesomorphy/ } \\
\text { Somewhat or not ectomorphy/ } \\
\text { Not endomorphy }\end{array}$ & Regular & $1238(34.0)$ \\
\hline $\begin{array}{c}\text { Shape 4: } \\
\text { Short Round Top Shape (SRTS) }\end{array}$ & Endomorphy & Portly \& Stout & $326(9.0)$ \\
\hline Total & & & $3686(100.0)$ \\
\hline
\end{tabular}

(SS) was characterized by the height length factor (SS factor 2 score $=0.1640$ ) and the girth factor (SS factor 1 score $=-0.5023)$. This body shape described a tall body in a normal or light weight range which 
Table 6. Average factor scores and computed values by the shape group

\begin{tabular}{c|c|c|c|c|c|c|c|c}
\hline Factor Score & $\begin{array}{c}\text { Girth } \\
\text { factor score }\end{array}$ & $\begin{array}{c}\text { Height } \\
\text { factor score }\end{array}$ & $\begin{array}{c}\text { Torso } \\
\text { length } \\
\text { factor score }\end{array}$ & $\begin{array}{c}\text { Degree } \\
\text { factor score }\end{array}$ & BMI & $\begin{array}{c}\text { Drops } \\
\text { (Difference: } \\
\text { Chest-Waist) }\end{array}$ & $\begin{array}{c}\text { Difference: } \\
\text { Hip-Waist }\end{array}$ & $\begin{array}{c}\text { Difference: } \\
\text { Hip-Chest }\end{array}$ \\
\hline Slim Shape (SS) & -0.5023 & 0.8564 & 0.1640 & -0.3347 & 24.11 & 5.95 & 5.44 & -0.51 \\
\hline Heavy Shape (HS) & 0.8705 & -0.2623 & 0.7269 & -0.1579 & 31.78 & 5.41 & 3.28 & -2.13 \\
\hline Slant Inverted Triangle Shape (SITS) & -0.5262 & -0.6848 & -0.1465 & 0.5196 & 25.40 & 6.44 & 5.25 & -1.18 \\
\hline Short Round Top Shape (SRTS) & 1.1874 & 0.3511 & -2.1844 & -0.3201 & 32.89 & 3.77 & 4.11 & 0.35 \\
\hline
\end{tabular}

Table 7. Average body dimensions in each body shape group

(Unit: Inches)

\begin{tabular}{c|c|c|c|c|c|c|c|c|c|c|c|c}
\hline Body dimensions & $\begin{array}{c}\text { Weight } \\
\text { (lbs.) }\end{array}$ & Chest & Hips & Waist & $\begin{array}{c}\text { Across } \\
\text { Shoulder }\end{array}$ & $\begin{array}{c}\text { Crotch } \\
\text { Height }\end{array}$ & $\begin{array}{c}\text { Waist } \\
\text { Height }\end{array}$ & Height & $\begin{array}{c}\text { Waist } \\
\text { Length } \\
\text { (Front) }\end{array}$ & $\begin{array}{c}\text { Waist } \\
\text { Length } \\
\text { (Back) }\end{array}$ & $\begin{array}{c}\text { Crotch } \\
\text { Length } \\
\text { Total }\end{array}$ & $\begin{array}{c}\text { Shoulder } \\
\text { Slope } \\
\text { (Degrees) }\end{array}$ \\
\hline Slim Shape (SS) & 174.0 & 40.6 & 40.0 & 34.6 & 16.3 & 32.2 & 41.9 & 71.2 & 18.1 & 20.7 & 26.3 & 22.6 \\
\hline Heavy Shape (HS) & 216.6 & 46.6 & 44.5 & 41.2 & 18.1 & 29.7 & 39.0 & 69.2 & 20.8 & 21.4 & 26.7 & 22.5 \\
\hline Slant Inverted Triangle Shape (SITS) & 159.7 & 40.5 & 39.3 & 34.0 & 16.5 & 29.2 & 38.4 & 66.5 & 17.6 & 19.8 & 25.0 & 25.1 \\
\hline Short Round Top Shape (SRTS) & 225.7 & 46.5 & 46.9 & 42.7 & 17.8 & 30.7 & 44.2 & 69.5 & 14.9 & 18.3 & 36.1 & 22.1 \\
\hline
\end{tabular}

means it was leaner than the other shapes (Fig. 2). Men who fell into this category tended to have chest sizes that were almost equal to hip size and were noted for their lack of muscularity (ectomorphy). The average drop for this group was 5.95 inch.

The Heavy Shape (HS) was best characterized by the girth factor (HS factor 1 score $=0.8705$ ) and the torso factor (HS factor 3 score $=0.728$ ). As shown in $<$ Table $6>-<$ Table $7>$, individuals with this shape had a large obese body, which was supported by an average BMI value of 31.78 . The chest was larger than the waist and the hips and the average drop value was $5.41 \mathrm{inch}$. This shape could be described as a combination of mesomorphy (muscularity and ruggedness) and endomorphy (softness and obesity). In the HS group, men might fit into either the big \& tall or athletic categories (Fig. 2).

The Slant Inverted Triangle Shape (SITS) was characterized by the girth factor (SITS factor $1=-0.5262$ ), the height length factor (SITS factor $2=-0.6848$ ), and the shoulder slope degree factor (SITS factor $4=$ $0.5196)$. As shown in $\langle$ Fig. $2>$, this body shape had a lower shoulder and shorter legs, were in the normal to slightly overweight range and had a slight inverted

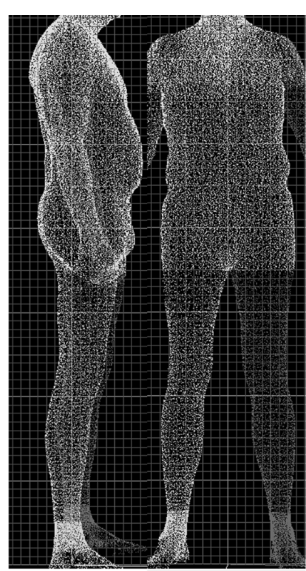

(a) Slim shape

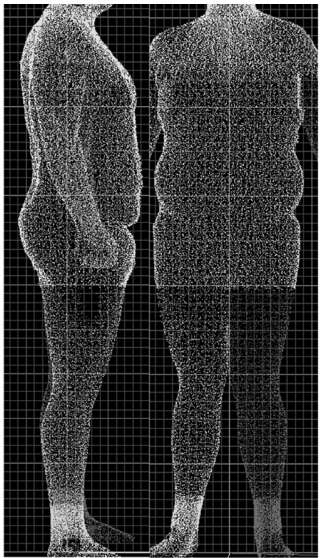

(b) Heavy shape

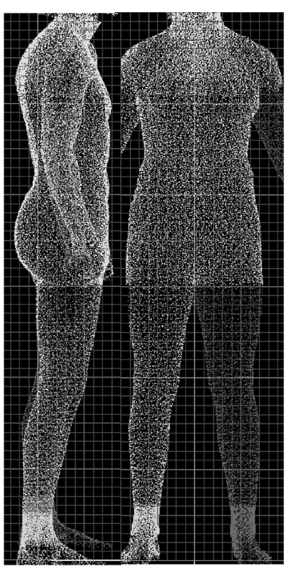

(c) Slant inverted-triangle shape

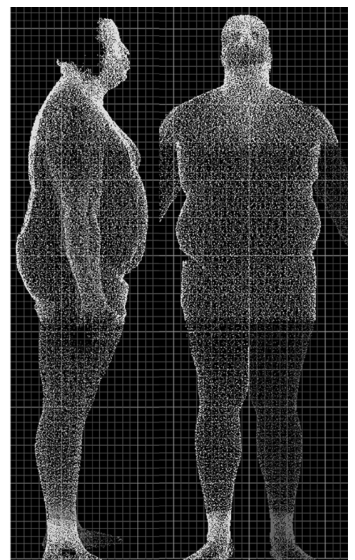

(d) Short round top shape

Fig. 2. Men's body shapes by factor and cluster analysis. 
triangle shape $<$ Fig. $2>$. The lower shoulder slope made them less mesomorphic in shape. The average drop (6.44 inch) was larger than other shapes and contributed to the appearance of an inverted triangle. As shown in $<$ Table $6><$ Table $7>$, compared to the hips, the chest shows an average 1.18 inch difference. In the SITS group, the men's shape could be described as falling somewhere between ectomorphy and mesomorphy. These subjects still have a chest that is larger than the waist but are somewhat less muscled than a true mesomorph (Fig. 2).

The Short Round Top Shape (SRTS) was best characterized by the girth factor (SRTS factor $1=$ 1.1874 ) and the torso factor (SRTS factor $3=-2.1844$ ). This shape could be described as endomorphy, showing softness and obesity in average BMI 32.89. As shown in $\langle$ Fig. 2$\rangle$, the waist lengths (both back and front) are shorter but the crotch length is longer than other body shapes. A short back waist length and longer crotch length contributed to the look of short round top shape in the side view (Fig. 2). The average drop ( 3.77 inch) was smaller than other shapes. The most noticeable characteristic of this group was that the hip was larger than the waist and the chest. Portly men and stout men were commonly found in this group.

\section{Conclusions}

The findings of this study revealed that the menswear industry is dealing with a wide range of fitting such as regular, big \& tall, athletic, stocky, and portly. However, at present, ASTM D6240: Standard tables of body measurements for men sizes thirty-four to sixty was the only standard available for menswear manufacturers and retailers in the United States. The ASTM D6240 standard is based on a regular body type which has a larger chest then waist, depicting a body that has a slant inverted triangle shape.

In the findings, the ASTM D 6240 standard provided a consistent six inch drop for the general sizes (from Small to Large) and smaller drops ranging from 5.5 inch to 2 inch for XL sizes. The average drops of SizeUSA men in each chest size group were not different compared to the average drops of ASTM in sizes ranging from 34 to 60 . Thus, the ASTM D 6240 standard for menswear sizes seemed to be acceptable according to the statistical analysis, although it should be noted that within a particular chest size group the drop did vary. Compared to the ASTM standard, SizeUSA men in the small size group had smaller drops (4.75 inch). We found the largest variability in drop size within the larger sizes. As an example, we found that drops in the $3 \mathrm{XL}$ size group ranged from -2.15 to 11.65 inches, indicating that the standard 6 inch drop would not be applicable for large sizes. It also indicates that fit problems are more likely with extra large sizes in regular fitting or other fitting categories such as big, tall, portly, or stout.

We attempted to build a general model of the average man's upper body shape based on BMI and drops, and concluded our data best described an individual who was in the overweight BMI category and had a slant inverted triangle shape. However, this model was too simplistic to describe the 'average body shape' since there were large standard deviations that accompanied our BMI and drop data Sheldon's somatotype model was evaluated as a possible method to describe men's body shapes in a graphical view. We determined that his method was useful, but limited in its ability to describe the men's body shapes across all categories. For example, it was not an effective way to categorize men's body types in menswear categories such as big \& tall or stout.

According to factor analysis of body dimensions, we found four factors that were important in providing us with an ability to categorize men's body shapes into distinct groups. Based on the results of factor scores and cluster analysis, men's body shapes were categorized into the following four body shape groups and each average drop value.

- Slim Shape (SS): This shape could be characterized as tall, ectomorphic. The average drop value was 5.95 inch.

- Heavy Shape (HS): Men with this shape could fall into the athletic or big \& tall categories and had either endomorphic or mesomorphic classifications. The average drop value was $5.41 \mathrm{inch}$.

- Slant Inverted Triangle Shape (SITS): This shape could be characterized as lying somewhere between 
ectomorphy and mesomorphy with weight ranging from normal to slightly overweight BMI. The lower shoulder shape made them look less mesomorphic, and they would fit best into the regular category. The average drop (6.44 inch) was larger than other shapes. The large drop was the biggest factor contributing to the look of an inverted triangle.

- Short Round Top Shape (SRTS): This shape could be characterized as endomorphic, overweight according to BMI, and could fit into the portly or stout menswear fitting category. The average drop value was 3.77 inch.

Overall, we found the body shape characteristics to be a useful way to define body types. In this study $34 \%$ of SizeUSA men were determined to have a Slant inverted triangle shape, 31\% had a Slim Shape, 26\% had a Heavy Shape, and 9\% had a Short Round Top Shape. Those subjects with a Slant Inverted Triangle Shape (34\%) could be accommodated in the regular menswear fitting category, although clearly the majority of men with this shape would not fall into this category. The Slim Shape and Heavy Inverted Triangle Shape $(57 \%)$ were related to the current big \& tall category. The Short Round Top Shape (9\%) was related to the portly and stout category.

Drops also varied according to the different body shape groups. Those with a Slant Inverted Triangle Shape (similar to regular category) still had a drop of almost six inches. However, the average drop in the Heavy Shape (similar to big \& tall category) was 5.4 inch, and the average drop in the Short Round Top Shape (similar to portly or stout category) was 3.7 inch. Taken together, our data suggests that the six inch drop is not a universal standard for the regular fitting category or for any other special category.

For the industry to increase or decrease drops without understanding the finer characteristics of men's body shapes and how body shape is effected by demographic factors would be meaningless. The ignorance of various men's body shapes impacts the development of menswear sizing systems and associated fit problems in the United Sates. In the United States, currently there is no ASTM standard for the special categories such as tall, big \& tall, portly, and stout
Demographic factors contribute to the increased number of men who will no longer be accommodated in the Regular category of clothing. Therefore, it is important that research along these lines be continued with the goal of developing appropriate menswear sizing systems for the special categories. The industry should also continue to evaluate the possibility that additional ASTM standards be developed that apply to these other categories. In addition, apparel manufacturers need to be sensitive to understanding how changing body shapes will impact on grading patterns, sizing systems, and the fitting of garments.

\section{Limitations and Future Research}

ASTM established the menswear standard D 6240 well before any of the major national sizing studies were conducted. They continue to evaluate the sizing standards, but it is a challenge for apparel manufacturers and retailers to set size ranges and grading rules to fit every body shape. Interestingly, there is no significant motivation for many who sit on the sizing standards committee to create a set of standards that actually work, since sizing can be a marketing tool for a Brand. Thus, there are still significant menswear markets with fit issues that need to be evaluated and modeled.

Due to the complexity of the human body form, the methodology used in this study may not be sufficient to explain, or even uncover all the other possible variables. Further research needs to be conducted to evaluate these variables according to established and as yet developed fit models and 3D technologies.

\section{References}

Aldrich, W. (1980). Metric pattern cutting for menswear: Including unisex clothes and computer aided design ( $3^{\text {rd }}$ ed.). Cambridge, Massachusetts: Blackwell Science.

Alexander, M., Connell, L. J., \& Ulrich, P. V. (2004). Using three-dimensional body scan data for body shape and body build analysis. Proceedings of the International Textile and Apparel Association, USA, 61, 5-6.

ASTM. (2006). ASTM D6240: Standard tables of body measurements for men sizes thirty-four to sixty (34 to 60) regular. American Society of Testing Material International Standard, 7(2), 1-6. doi:10.1520/D6240-98R06 
Boswell, S. (1993). Menswear suiting the customer. Englewood Cliffs, New Jersey: Prentice Hall.

Business Wire. (2007, November 14). Global luxury goods market growing at $9 \%$ per year despite uncertain signals. SmartBrief. Retrieved July 15, 2011, from http:// www. smartbrief.com/news/aaaa/industryBW-detail.jsp?id= F8FCA1B6-2F01-4D89-9FD9-1D668CF7AE02

Chan, A. P., Fan, J., \& Yu, W. M. (2005). Prediction of men's shirt pattern based on 3D body measurements. International Journal of Clothing Science and Technology, 17(2), 100-108.

Connell, L., Ulrich, P., Knox, A., Hutton, G., Woronka, D., \& Ashdown, S. (2002, November). Body scan analysis for fit models based on body shape and posture analysis (S01-AC27). South Carolina: National Textile Center Annual Report.

Cooklin, G. (1992). Pattern Grading for men's clothes: the technology of sizing. Cambridge, MA: Blackwell Scientific Publications.

Dickerson, K. (2003). Inside the fashion business ( $7^{\text {th }}$ ed.). Upper saddle River, New Jersey: Pearson Education.

Douty, H. I., Moore, J. B., \& Hartford, D. (1974). Body characteristics in relation to life adjustment, body-image and attitudes of college females. Perceptual and Motor Skills, 39, 499-521.

Farrell-Beck, J. A., \& Pouliot, C. J. (1983). Pant alteration by graphic somatometry techniques. Home Economics Research Journal, 12(1), 95-105.

Fringe, G. S. (2005). Fashion from concept to consumer $\left(8^{\text {th }}\right.$ ed.). Upper saddle River, New Jersey: Pearson Education.

Glock, R. E., \& Kunz, G. (2005). Apparel manufacturing sewn product analysis $\left(4^{\text {th }}\right.$ ed.). Upper saddle River, New Jersey: Person Education.

Heisey, F. L., Brown, P., \& Johnson, R. F. (1986). A mathematical analysis of the graphic somatometry method of pattern alteration. Home Economics Research Journal, 15(2), 115-122.

Kim, I. (2003). Ease and ethnicity: Important variables in good pants fit. Proceedings of International Textile and Apparel Association Annual Conference, USA, 60, 62.

Kolesnikov-Jessop, S. (2010, January 28). It's a man's world. Newsweek. Retrieved January 30, 2010, from http://www. newsweek.com/id/232695

Lee, J. H. (2004). Analysis of head shape of college students for the headgears, Journal of the Korean Society of Clothing and Textiles, 28(1), 182-188.

National Institute of Health. (2006). Body mass index. NIH. Retrieved November 26, 2006, from http://www.nhlbi. nih.gov/guidelines/obesity/bmitbl.htm

Rueters. (2010, January 31). Hopes for 2010 fashion recovery at Milan menswear. Business World. Retrieved July 15, 2011, from http://www.bworldonline.com/main/content.php?id $=5073$

Sheldon, W. H. (1954). Atlas of men: A guide for somatotyping the adult male at all ages. New York: Harper and Brothers.

Shin, S., \& Istook, C. (2007). Importance of understanding the shape of diverse ethnic female consumers for developing jeans sizing systems. International Journal of Consumer Studies, 31, 135-143.

Sieben, W. A., \& Chen-Yu, H. J. (1992). The accuracy of size information on men's prewashed jeans. Clothing and Textiles Research Journal, 11(1), 74-82.

Simmons, K. P., Istook, C. L., \& Devarajan, P. (2004). Female figure identification technique (FFIT) for apparel part II: Development of shape sorting software. Journal of Textile and Apparel Technology and Management, 4 (1). Retrieved July 15, 2011, from http://www.tx.ncsu. edu/jtatm/volume4issue1/articles/Istook/Istook_full_107_ 04.pdf

Stan, G. (2005, November 28). Fit remains key problem for B\&T men. DNR: Daily News Record, 35(48), 1-2.

Stone, E. (2007). Infashion fun fame fortune. New York: Fairchild publications, Inc.

Stone, E. (2008). The dynamics of fashion ( $3^{\text {rd }}$ ed.). New York: Fairchild publications, Inc.

Stunkard, A. J., \& Albaum, J. M. (1981). The accuracy of self-reported weights. American Journal of Clinical Nutrition, 34(8), 1593-1599.

Tate, S. L. (2004). Inside fashion design ( $5^{\text {th }}$ ed.). Upper saddle River, New Jersey: Pearson Education.

$[\mathrm{TC}]^{2}$. (2004). The national sizing survey: Body measurement and data analysis reports on the U.S. population. Cary, North Carolina: Author. 